CARTA AL DIRECTOR

\title{
Convulsiones mioclónicas y convulsiones tonicoclónicas generalizadas durante el tratamiento combinado con dosis bajas de clozapina y haloperidol
}

\author{
E. M. Haberfellner \\ Friedrichstraße 14, A-4040 Linz, Austria
}

\begin{abstract}
Aunque es bien sabido que los medicamentos antipsicóticos pueden reducir el umbral de convulsión, los medicamentos antipsicóticos tradicionales normalmente no afectan de manera sustancial al riesgo de convulsión. La clozapina tiene un riesgo de convulsión pertinente clínicamente, en especial en dosis medias y altas. Las dosis bajas de hasta $300 \mathrm{mg}$ de clozapina/d tienen una tasa de convulsiones del $1 \%$ aproximadamente [4]. Con el tratamiento con clozapina se producen también convulsiones mioclónicas sin pérdida de consciencia, seguidas a veces por convulsiones tonicoclónicas [5-7, 10]. La mayoría de los pacientes con convulsiones mioclónicas de los que se informa en las publicaciones recibían tratamiento con dosis diarias de clozapina de 300-600 mg [1-3, 6, 8-10]. El informe clínico siguiente describe convulsiones mioclónicas y una convulsión tonicoclónica generalizada durante el tratamiento con dosis bajas de clozapina y haloperidol.
\end{abstract}

\section{INFORME CLÍNICO}

Una mujer de 29 años con esquizofrenia de tipo paranoide había recibido tratamiento durante varios meses con $100 \mathrm{mg} / \mathrm{d}$ de clozapina y $10 \mathrm{mg} / \mathrm{d}$ de haloperidol. Este tratamiento se había iniciado en un hospital psiquiátrico y lo continuó un psiquiatra en consulta privada. Cuando la paciente acudió a una primera cita en la consulta psiquiátrica del autor, comunicó síntomas delirantes moderados. Por tanto, la dosis de clozapina se aumentó de $100 \mathrm{a} 150 \mathrm{mg} / \mathrm{d}$. La dosis de haloperidol de $10 \mathrm{mg} / \mathrm{d}$ se mantuvo igual. Como la paciente pretendía viajar a los EE.UU. sólo una semana después, un cambio sustancial de la medicación parecía inapropiado. Después de sus vacaciones, la paciente comunicó varias contracciones involuntarias repentinas de los músculos del hombro y el brazo a consecuencia de los cuales dejó caer objetos. Una vez experimentó una flexión repentina de las rodillas y cayó sin ninguna alteración de la consciencia u otras quejas. Algunos días después se produjo una convulsión tonicoclónica generalizada. La paciente no tenía antecedentes personales o familiares de epilepsia. Después de la reducción de la dosis de clozapina a $100 \mathrm{mg} / \mathrm{d}$ no tuvo más convulsiones o sacudidas mioclónicas. El EEG posterior a la reducción de la dosis mostró todavía patrones paroxísmicos (picos generalizados).

\section{DISCUSIÓN}

Comparado con los casos de convulsiones mioclónicas comunicadas en las publicaciones, la dosis de clozapina en mi paciente era baja $(150 \mathrm{mg} / \mathrm{d})$. Sólo dos autores comunican convulsiones mioclónicas por debajo de $300 \mathrm{mg}$ de clozapina: una con $200 \mathrm{mg}$ [2] 
y la otra con $250 \mathrm{mg}$ [10]. Tres de los casos comunicados en las publicaciones se habían tratado con clozapina en combinación con haloperidol. La co-medicación con haloperidol podría haber aumentado la vulnerabilidad a las convulsiones mioclónicas y de gran mal. Los pacientes y los psiquiatras pueden interpretar erróneamente las convulsiones mioclónicas como nerviosismo o síncope. Los informes de los pacientes de sacudidas mioclónicas durante el tratamiento con clozapina -incluso con dosis bajas- se deberían tomar seriamente, porque pueden ir seguidas de convulsiones tonicoclónicas generalizadas.

\section{BIBLIOGRAFÍA}

1 Antelo, ER, Stanilla JK, Martin-Llonch N. Myoclonic seizures and "leg folding" phenomena with clozapine therapy: report of two cases. Biol Psychiatry 1994; 36: 759-62.

2 Bak Th, Bauer M, Schaub RT, Hellweg R, Reischies FM. Myoclonus in patients treated with clozapine: a case series. J Clin Psychiatry 1995; 56: 418-22.
3 Berman 1, Zalma A, DuRand CJ, Green Al. Clozapineinduced myoclonic jerks and drop attacks. J Clin Psychiatry 1992; 53: 329-30.

4 Devinky O, Honigfeld G, Patin J. Clozapine-related seizures. Neurology 1991; 41: 369-71.

5 Devinsky 0, Pacia SV. Seizures during clozapine therapy. J Clin Psychiatry 1994; 55 (Suppl): 153-6.

6 Gouzoulis E, Grunze H, Bardeleben U. Myoclonic epileptic seizures during clozapine treatment: a report of three cases. Eur Arch Psychiatry Clin Neurosci 1991; 240: 370-2.

7 Haller E, Binder RL. Clozapine and seizures. Am J Psychiatry 1990; 147: 1069-71.

8 Meltzer HJ, Ranjan R. Valproic acid treatment of clozapine induced myoclonus. Am J Psychiatry 1994; 151: 1246-7.

9 Povlsen UJ, Noring U, Fog R, Gerlach J. Tolerability and therapeutic effect of clozapine. Acta Psychiatr Scand 1985; 71: 176-85.

10 Sajatovic M, Meltzer HY. Clozapine-induced myoclonus and generalized seizures. Biol Psychiatry 1996; 39: 36770 . 